\title{
A IMPENHORABILIDADE DO BEM DE FAMÍLIA À LUZ DO PRINCÍPIO DA EFETIVIDADE DA TUTELA EXECUTIVA: ANÁLISE DO POSICIONAMENTO DO SUPERIOR TRIBUNAL DE JUSTIÇA ${ }^{1}$
}

\section{THE IMPENHORABILITY OF THE FAMILY PROPERTY IN THE LIGHT OF THE PRINCIPLE OF THE EFFECTIVENESS OF THE EXECUTIVE GUARDIAN: ANALYSIS OF THE POSITIONING OF THE SUPERIOR COURT OF JUSTICE}

Rosalina Moitta Pinto da Costa Doutora em Direito das Relações Sociais (PUC/SP). Mestre em Direito Agrário (UFPA). Especialista em Direito Ambiental (UFPA). Especialista em Direito Civil e Processo Civil (ESMPA). Professora permanente do Programa de PósGraduação stricto sensu em Direito da Universidade Federal do Pará (PPGD-UFPA). Belém/PA. E-mail: rosalina.costa@hotmail.com

Manuel Albino Ribeiro de Azevedo Junior Mestrando em Direito na Universidade Federal do Pará (UFPA), Pós-graduado em Direito Civil pela Pontifícia Universidade Católica (PUC) de Minas Gerais (2020). Pósgraduado em Direito Processual Civil Individual e Coletivo pelo Centro Universitário do Estado do Pará (Cesupa) (2018). Graduado em Direito pelo Cesupa (2015). Membro da Liga Acadêmica Jurídica do Pará (Lajupa). Advogado do Escritório Siqueira, Lima e Erichsen Advogados Associados. Belém/PA. E-mail: albinoazevedo.adv@gmail.com

RESUMO: O presente trabalho analisa a interpretação do STJ acerca da impenhorabilidade do bem de família. Reconhecendo a efetividade da tutela executiva como um direito

\footnotetext{
${ }^{1}$ Artigo recebido em 10/02/2021 e aprovado em 06/04/2021.
} 
fundamental decorrente da inafastabilidade da jurisdição, o STJ tem adotado outros critérios além da previsão legislativa das exceções à impenhorabilidade do bem de família, buscando uma ponderação dos direitos fundamentais do devedor, como a dignidade da pessoa humana, a moradia e o direito ao mínimo existencial, e de outros direitos que visam prestigiar o credor. Conclui-se que o reconhecimento do direito fundamental à efetividade da execução tem sido um critério de flexibilização da norma da impenhorabilidade.

PALAVRAS-CHAVE: Bem de família. Impenhorabilidade. Efetividade da tutela executiva. Dignidade da pessoa humana. Direito fundamental à efetividade.

ABSTRACT: The present work analyzes the interpretation of the Superior Court of Justice about the impenhorability of the family property. Recognizing the effectiveness of executive protection as a fundamental right resulting from the unfeasibility of the jurisdiction, the Superior Court of Justice has adopted other criteria in addition to the legislative provision for exceptions to the impenhorability of the family propery, seeking to weigh up the debtor's fundamental rights, such as the dignity of the human person, housing and the right to an existential minimum, and other rights that aim to honor the creditor. It is concluded that the recognition of the fundamental right to the effectiveness of enforcement has been a criterion for making the rule of non-enforceability more flexible.

KEYWORDS: Family property. Impenhorability. Effectiveness of executive guardianship. Dignity of human person. Fundamental right to effectiveness.

\section{INTRODUÇÃO}

O presente trabalho objetiva analisar como o instituto da impenhorabilidade do bem de família tem sido interpretado pelo Superior Tribunal de Justiça (STJ), à luz do princípio da efetividade da tutela executiva.

Inicia-se o trabalho estabelecendo as premissas para avaliação da efetividade da tutela executiva de acordo com o Código de Processo Civil e decorrente do princípio constitucional da inafastabilidade da jurisdição (art. $5^{\circ}$, inciso XXXV), prestigiando assim, 
uma interpretação das normas com vista a satisfação do crédito executivo, tal qual outros princípios fundamentais do processo.

A seguir, analisa-se o bem de família e a previsão de sua impenhorabilidade, a qual, embora prestigie direitos do devedor, como a dignidade humana, a proteção da família e o direito à moradia, representa um entrave ao direito do credor.

Em conclusão, enfrentam-se os posicionamentos que o STJ tem adotado sobre a impenhorabilidade do bem de família, analisando suas decisões e os critérios adotados. A pesquisa fora realizada através de levantamento bibliográfico nacional, bem como pela análise de julgados sobre a temática, realizando um paralelo entre estes e as normas processuais vigentes, para fins de analisar a interpretação que lhe é conferida pelo Superior Tribunal.

Portanto, com base na análise dos posicionamentos mais recentes do STJ e dos critérios adotados por essa Corte, o presente estudo verifica se o entendimento do STJ tem considerado a efetividade da tutela executiva como um fator determinante na contemplação ou não da impenhorabilidade do bem de família.

\section{EFETIVIDADE DA TUTELA EXECUTIVA COMO PRINCÍPIO FUNDAMENTAL DO PROCESSO}

Nas relações sociais, é imperioso observar as normas e as regras estabelecidas pelo Estado para viabilizar o convívio social, cuja transgressão geralmente importa na aplicação de uma sanção. Quando levados ao Judiciário, os descumprimentos das leis, das regras, dos pactos têm o condão de fazer com que o Estado confira guarida aos direitos atingidos, tutelando a parte que foi prejudicada pela inobservância de uma norma.

Reconhecida pelo Juiz a existência de um direito, é assegurada à parte credora a reparação pela violação desse direito, por meio da obrigação imposta ao devedor de cumprir uma obrigação ou de prestar uma indenização. O desrespeito da ordem judicial para satisfação de uma obrigação impele o Estado a recorrer aos meios necessários para tutelar o direito do credor.

O procedimento de satisfação forçada da obrigação inadimplida pelo devedor inserese em uma fase ou em um processo de execução, no qual, por meio de uma atividade 
eminentemente judicial, realiza-se a prestação que uma parte deveria ter efetuado em favor da outra. O Juiz atua substituindo o devedor, utilizando os bens do seu patrimônio para satisfazer o direito do credor ${ }^{2}$.

Em linhas gerais, pode-se dizer que a satisfação de um direito do credor filiava-se à observância de um procedimento preestabelecido pelo Estado, taxativamente fixado em lei. Contudo, sob a égide de novas tendências, consubstanciadas na nova legislação processual (Lei n. $\left.{ }^{\circ} 13.105 / 2015\right)$, a concepção do processo como mero procedimento, sob os parâmetros do legalismo ${ }^{3}$, foi sendo alterada e o processo civil passou a ser encarado como integrante de um sistema constitucional ${ }^{4}$.

Com efeito, o novo CPC apresenta algumas tendências de aperfeiçoamento de institutos a fim de consagrar os princípios constitucionais, sendo uma das suas mais relevantes a busca da maior efetividade ${ }^{5}$ do processo. $\mathrm{O}$ espaço processual torna-se assim um ambiente em que se procura não apenas a declaração do direito, mas, principalmente, a efetivação daquele direito, o efetivo alcance do bem jurídico. Supera-se, desse modo, a exacerbada preocupação que existia com a atividade de declarar o direito, sem a devida preocupação com sua efetivação ${ }^{6}$.

Sustentada na Constituição Federal (CF) de $1988^{7}$, a jurisdição processual afasta-se do ultrapassado objetivo de apenas obter a declaração de valores constitucionais

\footnotetext{
2 THEODORO JUNIOR, Humberto. Processo de execução e cumprimento da sentença. 29. ed. São Paulo: Leud, 2017, p. 35.

${ }^{3}$ GÓES, Gisele Santos Fernandes. Processo civil cooperativo. A Leitura: Caderno da Escola Superior da Magistratura do Estado do Pará, Belém, v. 5, n. 9, nov. 2012, p. 108.

${ }^{4}$ Guilherme Henrique Lage Faria assevera: "O processo constitucional coloca-se, assim, ao centro de toda a estrutura de atuação das garantias constitucionais, sendo, por conseguinte, o instrumento através do qual se dá o exercício de todas as funções do Estado, em especial, a função jurisdicional" (FARIA, Guilherme Henrique Lage. Negócios processuais no modelo constitucional de processo. Salvador: Juspodivm, 2016, p. 202).

${ }^{5}$ Leonardo Carneiro da Cunha assim conceitua a efetividade, diferenciando-a da eficácia: "[...] efetividade relaciona-se com o cumprimento das normas jurídicas: uma norma é efetiva quando seja cumprida por seus destinatários. Enquanto a eficácia é a aptidão para produzir efeitos, a efetividade constitui uma medida de concretização dos efeitos previstos na norma" (CUNHA, Leonardo Carneiro da. A previsão do princípio da eficiência no projeto do novo Código de Processo Civil brasileiro. Revista de Processo, São Paulo, v. 39, n. 233, jul. 2014, p. 68).

${ }^{6}$ MINAMI, Marcos Youji. Tradição jurídica e efetivação das decisões judiciais: repercussões da tradição civil law na efetivação das decisões no Direito Brasileiro. In: TALAMINI, Eduardo; MINAMI, Marcos Youji (org.). Medidas executivas atípicas. Salvador: Juspodivm, 2018, p. 562. (Coleção Grandes Temas do NCPC, 11).

7 Eduardo Cambi, Adriane Haas e Nicole Schmitz asseveram: "O CPC/2015 concretiza uma abordagem neoconstitucional do processo civil, concepção esta que pode ser extraída logo de seu primeiro dispositivo, que apresenta o processo civil ordenado, disciplinado e interpretado conforme os valores e normas fundamentais estampados na Constituição Federal. Trata-se de regra que, expressamente, imprime a construção de um processo civil enraizado com os direitos fundamentais" (CAMBI, Eduardo; HAAS, Adriane; Schmitz, Nicole.
} 
Revista Eletrônica de Direito Processual - REDP.

Rio de Janeiro. Ano 15. Volume 22. Número 3. Setembro a Dezembro de 2021

Periódico Quadrimestral da Pós-Graduação Stricto Sensu em Direito Processual da UERJ

Patrono: José Carlos Barbosa Moreira (in mem.). ISSN 1982-7636. pp. 958-980

www.redp.uerj.br

normatizados ${ }^{8}$ e volta-se mais para o ideário de concretização. $\mathrm{O}$ direito fundamental à tutela jurisdicional não significa apenas o direito ao meio executivo adequado, mas visa a concretude desse interesse, exigindo que a técnica processual seja estruturada para atingir às necessidades do direito material diante do caso concreto ${ }^{9}$.

A Jurisdição brasileira, que adotou essa nova acepção de processo, passa a pautar-se por um conjunto de princípios dispostos nos primeiros artigos do CPC (do art. 1. ${ }^{\circ}$ ao art. 12), buscando fazer com que eles sirvam de norte à interpretação de todas as normas do sistema ${ }^{10}$.

Nesse cenário, a efetividade da tutela executiva torna-se um grande tema do Direito Processual Civil ${ }^{11}$. Nessa linha, Fredie Didier Jr., Leonardo Carneiro da Cunha, Paula Sarno Braga e Rafael Alexandria Oliveira, ao abordarem a execução, afirmam que "o devido processo legal, cláusula geral processual constitucional, tem como um de seus corolários o princípio da efetividade: os direitos devem ser efetivados, não apenas reconhecidos. Processo devido é processo efetivo"12.

\footnotetext{
Normas fundamentais no novo Código de Processo Civil. Revista de Processo, São Paulo, v. 44, n. 290, abr. 2019, p. 99).

${ }^{8}$ MARINONI, Luiz Guilherme; ARENHART, Sérgio Cruz; MITIDIERO, Daniel. Novo curso de processo civil: teoria do processo civil. 3. ed. rev., atual. e ampl. São Paulo: Revista dos Tribunais, 2017. v. 1, p. 109.

9 "O direito fundamental à tutela jurisdicional, além de ter como corolário o direito ao meio executivo adequado, exige que os procedimentos e a técnica processual sejam estruturados pelo legislador segundo as necessidades do direito material e compreendidos pelo juiz de acordo com o modo como essas necessidades se revelam no caso concreto" MARINONI, Luiz Guilherme; ARENHART, Sérgio Cruz; MITIDIERO, Daniel. Novo curso de processo civil: teoria do processo civil. 3. ed. rev., atual. e ampl. São Paulo: Revista dos Tribunais, 2017. v. 1, p. 109, grifo nosso.

${ }^{10}$ Eduardo Cambi, Adriane Haas e Nicole Schmitz assim dispõem sobre as normas fundamentais do processo: "Portanto, o novo Código de Processo Civil foi estruturado para que os dispositivos iniciais emanem a direção que deve tomar a interpretação das regras seguintes, de cunho especialmente procedimental, para fazer com que todos os artigos estejam condizentes com a estrutura principiológica fundamental" (CAMBI, Eduardo; HAAS, Adriane; Schmitz, Nicole. Normas fundamentais no novo Código de Processo Civil. Revista de Processo, São Paulo, v. 44, n. 290, abr. 2019, p. 101).

${ }^{11}$ Bruno Marzullo Zaroni e Edilson Vitorelli bem expõem sobre o ponto primordial da atividade executiva: "A palavra de ordem em reação à atividade satisfativa, ou executiva, é efetividade. A missão da execução é facilmente sintetizável: entregar ao credor exatamente aquilo a que tem direito, no menor prazo possível, do modo menos oneroso possível para o devedor e para o sistema processual" (ZARONI, Bruno Marzullo; VITORELLI, Edilson. Reforma e efetividade da execução no novo CPC. In: MACÊDO, Lucas Buril de; PEIXOTO, Ravi; FREIRE, Alexandre (org). Execução. 2. ed. Salvador: Juspodivm, 2016, p. 54. (Coleção Novo CPC Doutrina Selecionada, 5)).

${ }^{12}$ DIDIER JR., Fredie; CUNHA, Leonardo Carneiro da; BRAGA, Paula Sarno; OLIVEIRA, Rafael Alexandria. Curso de Direito Processual Civil: execução. 7. ed. Salvador: Juspodivm, 2017. v. 5, p. 65.

Nesse sentido, explica Cássio Scarpinella Bueno: "O art. $4^{\circ}$ reproduz, no plano infraconstitucional, o 'princípio da economia e eficiência processuais' constante do art. $5^{\circ}$, LXXVIII, da CF, incluído pela EC n. 45/2004. A expressa menção a 'atividade satisfativa' é digna de destaque para evidenciar que a atividade jurisdicional não se esgota com o reconhecimento (declaração) dos direitos, mas também com sua concretização" (BUENO, Cassio Scarpinella. Novo Código de Processo Civil Anotado. São Paulo: Saraiva, 2015, p. 43-44)
} 
Então, revela-se de grande proveito para a legislação processual o artigo $4 .^{\circ}$ do CPC/2015, que estabelece: “As partes têm o direito de obter em prazo razoável a solução integral do mérito, incluída a atividade satisfativa".

O debate acerca da existência de um princípio da efetividade da tutela executiva torna-se central, com implicação em todos os dispositivos do Código, que incorpora como modelo de interpretação das normas processuais a verificação, pelo julgador, se o princípio da efetividade da tutela executiva está sendo prestigiado.

Os princípios constitucionais incidem diretamente no processo civil, como norteadores da interpretação das normas processuais. Fredie Didier $\mathrm{Jr}^{13}$ assevera que deve ser reconhecida a força normativa da Constituição, com eficácia imediata e independente dos princípios constitucionais, que deixam de ser técnica de integração do direito e passam a ser uma espécie de norma jurídica.

Nessa mesma esteira, Jean Carlos Dias et al. confirmam a eficácia imediata dos direitos fundamentais no direito processual, apontando que "nenhum livro em matéria processual pode ser iniciado sem fazer recurso a um estudo preliminar acerca dos direitos fundamentais e suas implicações à atuação dos jurisdicionados [...]"14.

Então, a partir de uma interpretação do próprio direito constitucional, notadamente do princípio da inafastabilidade da jurisdição, estabelecido no artigo $5^{\circ}, \mathrm{XXXV}$, da CF, a efetividade da tutela executiva deve ser um norte da atividade judicial, que tem como função precípua receber os pleitos, declarar o direito existente e, principalmente, confirmar o cumprimento desse direito por meio da tutela executiva ${ }^{15}$.

A existência, portanto, de um direito fundamental para a efetividade da tutela executiva advém de uma interpretação do processo civil conforme os princípios constitucionais ${ }^{16}$, segundo os quais o direito de acesso à justiça compreende o direito não

\footnotetext{
${ }^{13}$ DIDIER JR., Fredie. Curso de Direito Processual Civil: introdução ao Direito Processual Civil, parte geral e processo de conhecimento. 19. ed. Salvador: Juspodivm, 2017, p. 48.

${ }^{14}$ DIAS, Jean Carlos; MOUTA, José Henrique; SILVA, Michel Ferro e; SILVA, Adelvan Oliverio; HOMCI, Arthur Laércio; PEREIRA, Bernardo Augusto da Costa. Curso de Processo Civil: processo de conhecimento. Rio de Janeiro: Lumen Juris, 2016, p. 6.

${ }^{15}$ Marcelo Abelha Rodrigues é incisivo: "[...] enquanto a crise de adimplemento não é definitivamente satisfeita, não há que se falar em tutela jurisdicional integral. Convidar para entrar em juízo e não fornecer o caminho de saúde, deixando o jurisdicionado num labirinto sem saída, é um engodo inadmissível num Estado Democrático de Direito" (RODRIGUES, Marcelo Abelha. Fundamentos da tutela executiva. Brasília, DF: Gazeta Jurídica, 2018, p. 24).

${ }^{16} \mathrm{~A}$ inclusão do direito a uma tutela jurisdicional efectiva no catálogo dos direitos fundamentais é hoje bastante frequente" SOUZA, Miguel Teixeira de. A reforma da acção executiva. Lisboa: Lex, 2004, p.19-20
} 
somente a uma sentença judicial, mas, principalmente, à concretização da norma jurídica individualizada no plano da realidade, com a concretização do direito na prática ${ }^{17}$.

Esse preceito constitucional (art. 5. ${ }^{\circ}$, inciso XXXV, da Constituição Federal) é incorporado no novo CPC (art. $3^{\circ}$ ), imprimindo mudanças na técnica processual e na atividade executiva do juiz e, assim, exigindo uma nova compreensão de direito fundamental à tutela jurisdicional efetiva no procedimento executivo ${ }^{18}$. Reflexo de um fenômeno muito mais amplo, que tem origem na percepção de que o direito à efetividade da tutela jurisdicional deve ser enquadrado entre os direitos fundamentais e, como corolário, incide diretamente tanto na esfera de responsabilidade do legislador quanto do juiz, a fim de dar efetividade a proteção ao direito material ${ }^{19}$.

O princípio da efetividade, ora ratificado pelo $\mathrm{CPC}$, garante o direito fundamental à tutela executiva; logo, os direitos devem ser efetivados, e não apenas reconhecidos, o que acaba repercutindo na solução das diversos situações do procedimento executivo, principalmente aqueles relacionados à aplicação das regras de proteção do executado ${ }^{20}$.

\footnotetext{
${ }^{17} \mathrm{O}$ art. $5^{\circ}, \mathrm{XXXV}$ da Constituição Federal estabelece que "a lei não excluirá da apreciação do Poder Judiciário lesão ou ameaça a direito" (destacamos). Falar-se em jurisdição estatal destituída de instrumentos que permitam realizar materialmente o direito, através de atos executivos, implicaria reduzir significativamente sua importância e razão de ser, especialmente se se considerar que, na sociedade moderna, cada vez maior tem sido a preocupação com a concretização dos direitos. De outro lado, espera-se, com a tutela jurisdicional, a realização de atividade condizente com o direito material ameaçado ou violado, não mais se admitindo que o direito se considere realmente tutelado com a mera declaração de que houve violação ou há ameaça". MEDIDA, Jose Miguel Garcia. 5. ed. Execução. São Paulo: Revista dos Tribunais, 2017, p. 28

${ }^{18}$ Nesse sentido, Rodrigo Regis Mazzei e Marcelo da Rocha Rosado (2018, p. 501-502) explicam: "Essencial entender, também, que a cláusula que garante o acesso à jurisdição em nosso ordenamento (art. $5^{\circ}, \mathrm{XXXV}$, CF/88), em sua noção mais moderna, possui dimensão que lhe confere eficácia que vai além de garantir uma simples resposta do Poder Judiciário, pois também remete à necessidade de se municiarem o jurisdicionado e o próprio órgão jurisdicional com técnicas processuais adequadas para a tutela do direito material, com efetiva transformação da realidade - meta assumida pelo $\mathrm{CPC} / 15$. Portanto, para a concretização do direito fundamental do acesso à jurisdição, é essencial que o sistema seja moldado de forma a que o processo seja instrumento a garantir uma tutela jurisdicional adequada, efetiva e tempestiva dos direitos" (MAZZEI, Rodrigo Reis; ROSADO, Marcelo da Rocha. A cláusula geral de efetividade e as medidas indutivas no CPC/15. In: TALAMINI, Eduardo; MINAMI, Marcos Youji (coord.). Medidas executivas atípicas. Coleção Grandes Temas do Novo CPC. Vol. 11. Salvador: JusPodivm, 2018, p. 501-502)

19 "O estudo do procedimento executivo no novo CPC pressupõe que se compreenda, ainda em que em linha de extrema generalização, como o direito fundamental à tutela jurisdicional efetiva (art. $5^{\circ}$, inciso XXXV, da Constituição Federal) imprime mudanças na técnica processual e na atividade executiva do juiz, notadamente porque a novel legislação incorpora expressamente tal preceito constitucional" ZARONI, Bruno Marzullo; VITORELLI, Edilson. Reforma e efetividade da execução no novo CPC. In: MACÊDO, Lucas Buril de; PEIXOTO, Ravi; FREIRE, Alexandre (org). Execução. 2. ed. Salvador: Juspodivm, 2016, p. 59. (Coleção Novo CPC Doutrina Selecionada, 5)).

${ }^{20}$ DIDIER JR., Fredie; CUNHA, Leonardo Carneiro da; BRAGA, Paula Sarno; OLIVEIRA, Rafael Alexandria. Curso de Direito Processual Civil: execução. 7. ed. Salvador: Juspodivm, 2017. v. 5, p. 65-66, grifo nosso.
} 
Rio de Janeiro. Ano 15. Volume 22. Número 3. Setembro a Dezembro de 2021

Periódico Quadrimestral da Pós-Graduação Stricto Sensu em Direito Processual da UERJ

Patrono: José Carlos Barbosa Moreira (in mem.). ISSN 1982-7636. pp. 958-980 www.redp.uerj.br

Portanto, analisar a tutela executiva como um direito fundamental impõe que sejam garantidos meios que promovam a efetividade da tutela jurisdicional, papel que cabe precipuamente ao Estado $^{21}$.

Com esse foco, a atividade executiva ganha novos contornos, assumindo maior importância na ciência processual, a fim de viabilizar técnicas processuais que sejam capazes de garantir uma maior efetivação do direito ${ }^{22}$.

Compreender que a efetividade da execução é um direito fundamental do processo ou uma manifestação direta do princípio constitucional da inafastabilidade da jurisdição é imperioso para a própria credibilidade do processo e do Poder Judiciário, com o fito de elevar a relevância da atividade satisfativa a patamar que lhe é devido, possivelmente a fase mais relevante em muitos processos, quando o credor objetiva efetivar o direito que lhe foi garantido.

Nesse contexto, o presente estudo analisa, notadamente, se o conteúdo do princípio da efetividade da tutela executiva, que se manifesta por meio do emprego das técnicas processuais e da interpretação das normas de acordo com a busca da efetivação do direito do credor, está sendo adotado no ordenamento jurídico nacional.

Assim, considerando que o direito à efetividade da tutela executiva é um direito fundamental, que incide na esfera de responsabilidade do legislador e do juiz, de forma a dar completa proteção ao direito material, passa-se, na seção seguinte, a analisar se a impenhorabilidade do bem de família tem relação com o princípio da efetividade da tutela executiva.

\section{A IMPENHORABILIDADE DO BEM DE FAMÍlIA COMO TÉCNICA LIMITATIVA DO PRINCÍPIO DA EFETIVIDADE DA TUTELA EXECUTIVA}

\footnotetext{
${ }^{21}$ Sobre esse papel do Estado, afirmam Bruno Marzullo Zaroni e Edilson Vitorelli: “[...] cabe ao Estado, sobre o inafastável influxo do direito fundamental à tutela jurisdicional efetiva, preordenar meios de garantir a utilidade prática de suas próprias decisões judiciais, assegurando, em última análise, meios executivos que provejam efetividade à tutela jurisdicional" (ZARONI, Bruno Marzullo; VITORELLI, Edilson. Reforma e efetividade da execução no novo CPC. In: MACÊDO, Lucas Buril de; PEIXOTO, Ravi; FREIRE, Alexandre (org). Execução. 2. ed. Salvador: Juspodivm, 2016, p. 65. (Coleção Novo CPC Doutrina Selecionada, 5).

${ }^{22}$ SICA, Heitor Vitor Mendonça. Tendências evolutivas da execução civil brasileira. [2014?], p. 26. Disponível em: https://edisciplinas.usp.br/pluginfile.php/4425295/mod_resource/content/1/2014__Tendencias_evolutivas_da_execucao.pdf. Acesso em: 2 set. 2020.
} 
Revista Eletrônica de Direito Processual - REDP.

Rio de Janeiro. Ano 15. Volume 22. Número 3. Setembro a Dezembro de 2021

Periódico Quadrimestral da Pós-Graduação Stricto Sensu em Direito Processual da UERJ

Patrono: José Carlos Barbosa Moreira (in mem.). ISSN 1982-7636. pp. 958-980 www.redp.uerj.br

O estudo do bem de família abrange a manifestação de direitos fundamentais e opções políticas de proteção e guarida que o Estado confere à sociedade, promovendo segurança jurídica e privilegiando princípios como a proteção da dignidade da pessoa humana, da família e da propriedade privada.

As bases históricas do instituto do bem de família no Brasil estão enraizadas na legislação americana, mais precisamente no Homestead $A c t^{23}$ ou Lei de Terras, que data do século XIX. O instituto foi introduzido no Brasil pelo Código Civil de $1916^{24}$.

Maria Fernanda César Las Casas de Oliveira, Renata Maria Silveira Toledo e João Paulo Marques dos Santos ${ }^{25}$ definem o bem de família como um instituto híbrido, pois funde a proteção da pessoa humana com os direitos patrimoniais, visando proteger o "lar", o domicílio, o núcleo familiar.

\footnotetext{
${ }^{23}$ Fernando Natal Batista assim discorre sobre o Homestead: "O antecedente histórico mais significativo, que primeiro normatizou e disciplinou a proteção do bem de moradia familiar, foi o "Homestead Exemption Act", uma lei texana, datada de 26 de janeiro de 1838, cujo objetivo era proteger a propriedade dos pequenos produtores rurais dos agentes financeiros, evitando-se, assim, a desocupação territorial daquele ente federativo" (BATISTA, Fernando Natal. Considerações jurisprudenciais do Superior Tribunal de Justiça sobre a impenhorabilidade do bem de família legal à luz dos princípios da dignidade da pessoa humana e da proteção à moradia. Revista da AGU, Brasília, DF, v. 16, n. 3, jul./set. 2017, p. 182. Disponível em: https://www.academia.edu/34810070/Considera\%C3\%A7\%C3\%B5es_Jurisprudenciais_Do_Superior_Tribu nal_De_Justi\%C3\%A7a_Sobre_A_Impenhorabilidade_Do_Bem_De_Fam\%C3\%ADlia_Legal_\%C3\%80_Lu z_Dos_Princ\%C3\%ADpios_Da_Dignidade_Da_Pessoa_Humana_E_Da_Prote\%C3\%A7\%C3\%A3o_\%C3\% 80_Moradia. Acesso em: 2 set. 2020). Na mesma linha, afirma Araken de Assis: "A ideia de conferir 'isenção de execução por dívidas', equivalendo a outorgar impenhorabilidade à morada da família (homestead), surgiu no direito norte-americano, como produto auspiciosa consequência de gravíssima crise financeira restrição ao direito dos credores sobre o patrimônio do devedor" (ASSIS, Araken de. Manual de execução. 18. ed. São Paulo: Revista dos Tribunais, 2016, p. 353).

${ }^{24}$ Leciona Fernando Natal Batista: "No Brasil, a proteção ao bem de família foi introduzida e regulada pelo Código Civil de 1916 (artigos 70 a 73), que concedida [sic] às pessoas isentas de dívidas o direito de declarar, perante o Cartório de Registro de Imóveis, a destinação exclusiva de seu imóvel para seu domicílio e de sua família ('bem de família voluntário')" (BATISTA, Fernando Natal. Considerações jurisprudenciais do Superior Tribunal de Justiça sobre a impenhorabilidade do bem de família legal à luz dos princípios da dignidade da pessoa humana e da proteção à moradia. Revista da $A G U$, Brasília, DF, v. 16, n. 3 , jul./set. 2017, 2 p. $183 . \quad$ Disponível em: https://www.academia.edu/34810070/Considera\%C3\%A7\%C3\%B5es_Jurisprudenciais_Do_Superior_Tribu nal_De_Justi\%C3\%A7a_Sobre_A_Impenhorabilidade_Do_Bem_De_Fam\%C3\%ADlia_Legal_\%C3\%80_Lu z_Dos_Princ\%C3\%ADpios_Da_Dignidade_Da_Pessoa_Humana_E_Da_Prote\%C3\%A7\% C3\%A3o_\%C3\% 80_Moradia. Acesso em: 2 set. 2020).

${ }^{25}$ OLIVEIRA, Maria Fernanda César Las Casas de; TOLEDO, Renata Maria Silveira; SANTOS, João Paulo Marques dos. O Superior Tribunal de Justiça e a proteção do bem de família: ativismo judicial ou preservação do patrimônio mínimo? Revista da Defensoria Pública da União, Brasília, DF, n. 12, jan./dez. 2019, p. 252. Disponível em: https://www.academia.edu/40976340/O_SUPERIOR_TRIBUNAL_DE_JUSTI\%C3\%87A_E_A_PROTE\%C 3\%87\%C3\%830_DO_BEM_DE_FAM\%C3\%8DLIA_ATIVISMO_JUDICIAL_OU_PRESERVA\%C3\%87 \%C3\%83O_DO_PATRIM\%C3\%94NIO_M\%C3\%8DNIMO. Acesso em: 2 set. 2020.
} 
Rio de Janeiro. Ano 15. Volume 22. Número 3. Setembro a Dezembro de 2021

Periódico Quadrimestral da Pós-Graduação Stricto Sensu em Direito Processual da UERJ

Patrono: José Carlos Barbosa Moreira (in mem.). ISSN 1982-7636. pp. 958-980 www.redp.uerj.br

Por sua vez, Guilherme Calmon Nogueira da Gama e Thaís Boia Marçal ${ }^{26}$ enfatizam a necessidade de assegurar a sobrevivência digna dos integrantes da família, no mínimo existencial, uma vez que a família é a célula menor e fundamental da sociedade

A ideia da proteção do bem de família está bastante atrelada à proteção do mínimo existencial da pessoa, ou seja, àqueles direitos mínimos que qualquer ser humano tem de possuir, inerentes a sua própria qualidade de ser humano, para que então possa crescer e se desenvolver. A moradia é assim reconhecida por nosso ordenamento jurídico como um dos elementos do mínimo existencial.

Por isso, afirmam Maria Fernanda César Las Casas de Oliveira, Renata Maria Silveira Toledo e João Paulo Marques dos Santos que o bem de família configura uma seguridade ao patrimônio mínimo essencial do indivíduo, porque "é uma forma de afetação de bens, com objetivo de assegurar a dignidade humana e o direito à moradia de qualquer pessoa" $" 27$.

De igual modo, afiguram Fernando Natal Batista que o imóvel residencial da família, à luz do direito à moradia e da dignidade da pessoa humana, concretiza a tutela constitucional prevista em nossa Carta Política, pois "é muito mais do que apenas uma propriedade patrimonial, é inegavelmente um direito fundamental que deve ser protegido pela atividade jurisdicional estatal" ${ }^{\prime 28}$.

No que concerne à classificação da impenhorabilidade do bem de família, para Araken de Assis, trata-se de uma impenhorabilidade relativa ${ }^{29}$, porém, de forma adstrita, ou

\footnotetext{
${ }^{26}$ GAMA, Guilherme Calmon Nogueira da; MARÇAL, Thaís Boia. Penhorabilidade do bem de família "luxuoso" na perspectiva civil-constitucional. Revista Quaestio Iuris, Rio de Janeiro, v. 6, n. 2, 2013, p. 244. Disponível em: https://www.e-publicacoes.uerj.br/index.php/quaestioiuris/issue/view/814. Acesso em: 2 set. 2020).

27 OLIVEIRA, Maria Fernanda César Las Casas de; TOLEDO, Renata Maria Silveira; SANTOS, João Paulo Marques dos. O Superior Tribunal de Justiça e a proteção do bem de família: ativismo judicial ou preservação do patrimônio mínimo? Revista da Defensoria Pública da União, Brasília, DF, n. 12, jan./dez. 2019, p. 252. Disponível em: https://www.academia.edu/40976340/O_SUPERIOR_TRIBUNAL_DE_JUSTI\%C3\%87A_E_A_PROTE\%C 3\%87\%C3\%830_DO_BEM_DE_FAM\%C3\%8DLIA_ATIVISMO_JUDICIAL_OU_PRESERVA\%C3\%87 \%C3\%830_DO_PATRIM\%C3\%94NIO_M\%C3\%8DNIMO. Acesso em: 2 set. 2020.

28 BATISTA, Fernando Natal. Considerações jurisprudenciais do Superior Tribunal de Justiça sobre a impenhorabilidade do bem de família legal à luz dos princípios da dignidade da pessoa humana e da proteção à moradia. Revista da $A G U$, Brasília, DF, v. 16, n. 3, jul./set. 2017, p. 187. Disponível em: https://www.academia.edu/34810070/Considera\%C3\%A7\%C3\%B5es_Jurisprudenciais_Do_Superior_Tribu nal_De_Justi\%C3\%A7a_Sobre_A_Impenhorabilidade_Do_Bem_De_Fam\%C3\%ADlia_Legal_\%C3\%80_Lu z_Dos_Princ\%C3\%ADpios_Da_Dignidade_Da_Pessoa_Humana_E_Da_Prote\%C3\%Ā̄\%C3\%A30_\%C $3 \%$ 80_Moradia. Acesso em: 2 set. 2020.

${ }_{29}$ Araken de Assis aduz: "Existe impenhorabilidade relativa quando alguns bens, normalmente subtraídos à expropriação, haja vista fatores diversos, e em certas circunstâncias, sujeitam-se à excussão. Em síntese, a
} 
seja, "na qual o bem somente pode ser penhorado para o pagamento de determinadas dívidas" ${ }^{30}$.

Os próprios dispositivos legais já evidenciam a abrangência do instituto, que, acima de tudo, visa a não sujeição do bem imóvel destinado à moradia a riscos de perda ou de desfazimento da propriedade por débitos.

Nas palavras de Araken de Assis, a proteção conferida ao bem de família, fruto da humanização da execução, "recorta do patrimônio o mínimo indispensável à sobrevivência digna do obrigado" 31 .

A proteção conferida ao imóvel que serve de residência da entidade familiar é reconhecida como um direito fundamental, decorrente da dignidade da pessoa humana e do mínimo existencial. Assim, tal patrimônio não se submete a débitos de seu proprietário, configurando uma clara opção para o legislador fazer prevalecer os princípios da dignidade da pessoa humana, da moradia - assegurados, respectivamente, pelos artigos $1 .^{\circ}$, III, e $6 .^{\circ}$ da $\mathrm{CF}$ - e da proteção da entidade familiar ${ }^{32}$, em detrimento do direito ao crédito legítimo de terceiro contra o proprietário.

Para Fredie Didier Jr., Leonardo Carneiro da Cunha, Paula Sarno Braga e Rafael Alexandria Oliveira, a impenhorabilidade representa uma "restrição ao direito fundamental à tutela executiva" ${ }^{33}$. Segundo os autores, embora seja uma técnica que limite a atividade executiva, ela se justifica porque se afigura como meio de proteção de bens jurídicos relevantes, como a dignidade do executado, o direito ao patrimônio mínimo e a função social da empresa. Contudo, sendo uma técnica de restrição a um direito fundamental, sua

penetração do ato executivo no círculo patrimonial do obrigado obedece a etapas e requisitos fixados em lei, separando categorias de bens e selecionando situações, sob pena de invalidade" (ASSIS, Araken de. Manual de execução. 18. ed. São Paulo: Revista dos Tribunais, 2016, p. 318).

${ }^{30}$ ASSIS, Araken de. Manual de execução. 18. ed. São Paulo: Revista dos Tribunais, 2016, p. 316.

${ }^{31}$ ASSIS, Araken de. Manual de execução. 18. ed. São Paulo: Revista dos Tribunais, 2016, p. 358-359.

${ }^{32}$ Estabelece a Súmula 364 do STJ: "O conceito de impenhorabilidade de bem de família abrange também o imóvel pertencente a pessoas solteiras, separadas e viúvas". Ampliou-se o entendimento do imóvel a ser protegido - antes da Súmula 364, era tão somente aquele em que o "casal" ou a "entidade familiar" tinha sua moradia -, muito em decorrência do reconhecimento da diversidade de formações familiares, todas tendo direito à proteção do imóvel de moradia.

${ }^{33}$ DIDIER JR., Fredie; CUNHA, Leonardo Carneiro da; BRAGA, Paula Sarno; OLIVEIRA, Rafael Alexandria. Curso de Direito Processual Civil: execução. 7. ed. Salvador: Juspodivm, 2017. v. 5, p. 66. 
Rio de Janeiro. Ano 15. Volume 22. Número 3. Setembro a Dezembro de 2021

Periódico Quadrimestral da Pós-Graduação Stricto Sensu em Direito Processual da UERJ

Patrono: José Carlos Barbosa Moreira (in mem.). ISSN 1982-7636. pp. 958-980 www.redp.uerj.br

aplicação deve se submeter ao método da ponderação, a partir da análise das circunstâncias do caso concreto ${ }^{34}$.

Não se pode negar que a regra da impenhorabilidade, estabelecida pela legislação e decorrente da proteção de direitos fundamentais, guarda correspondência com outros direitos fundamentais, que devem ser observados. Trata-se, portanto, de técnica que limita o direito fundamental à tutela executiva.

Reduzir a análise da impenhorabilidade do bem de família a um viés formalista, apenas tendo como parâmetro o rol de exceções à impenhorabilidade previstas na Lei n. ${ }^{\circ}$ 8.009/1990, enseja a possibilidade de violações aos direitos fundamentais do credor, além do próprio direito à efetividade da execução (manifestação do princípio da inafastabilidade da jurisdição), também à razoabilidade e proporcionalidade ${ }^{35}$.

Fredie Didier Jr., Leonardo Carneiro da Cunha, Paula Sarno Braga e Rafael Alexandria Oliveira ${ }^{36}$ aduzem que as hipóteses de impenhorabilidade não podem incidir em determinados casos concretos, quando se evidenciarem a desproporção, a desnecessidade ou a inadequação entre a restrição a um direito fundamental e a proteção do outro. Defendem os autores que é papel do órgão julgador proceder ao controle de constitucionalidade in concreto, pois a lei aplicada ao caso concreto pode revelar-se inconstitucional, dada a possibilidade de violação de direitos fundamentais da outra parte. Portanto, segundo eles, o órgão jurisdicional deve fazer um controle de constitucionalidade in concreto da aplicação das regras de impenhorabilidade; se sua aplicação revelar-se inconstitucional, por violação da razoabilidade ou da proporcionalidade, a impenhorabilidade deve ser afastada no caso, prevalecendo os direitos do credor em detrimento da proteção do devedor ${ }^{37}$.

Assim, não se trata da prevalência absoluta da regra da impenhorabilidade e dos princípios fundamentais que a embasam, em detrimento dos demais princípios que fundamentam a atividade executiva. De fato, a limitação ao princípio da efetividade da

\footnotetext{
34 DIDIER JR., Fredie; CUNHA, Leonardo Carneiro da; BRAGA, Paula Sarno; OLIVEIRA, Rafael Alexandria. Curso de Direito Processual Civil: execução. 7. ed. Salvador: Juspodivm, 2017. v. 5, p. 66, grifo nosso.

${ }^{35} \mathrm{CPC}$, art. 8. ': “Ao aplicar o ordenamento jurídico, o juiz atenderá aos fins sociais e às exigências do bem comum, resguardando e promovendo a dignidade da pessoa humana e observando a proporcionalidade, a razoabilidade, a legalidade, a publicidade e a eficiência".

36 DIDIER JR., Fredie; CUNHA, Leonardo Carneiro da; BRAGA, Paula Sarno; OLIVEIRA, Rafael Alexandria. Curso de Direito Processual Civil: execução. 7. ed. Salvador: Juspodivm, 2017. v. 5, p. 66-67.

37 DIDIER JR., Fredie; CUNHA, Leonardo Carneiro da; BRAGA, Paula Sarno; OLIVEIRA, Rafael Alexandria. Curso de Direito Processual Civil: execução. 7. ed. Salvador: Juspodivm, 2017. v. 5, p. 66-67.
} 
execução apenas pode advir de uma conjunção da norma legal e da prevalência dos princípios fundamentais que a fundamentam, em contrapartida aos princípios que se manifestam em favor do credor no caso.

Exemplo desse conflito são os casos de bem de família de alto valor, nos quais os direitos à dignidade, ao mínimo existencial e à moradia do devedor estariam mitigados em comparação com os direitos fundamentais do credor. Guilherme Calmon Nogueira da Gama e Thaís Boia Marçal $^{38}$ ressaltam que a impossibilidade de penhora do bem de família luxuoso afronta a razoabilidade por não guardar proporcionalidade entre o direito do devedor (direito a um patrimônio vasto, que excede o limite do necessário a um padrão médio de vida digna) e o direito do credor sacrificado (sua pretensão executiva).

Concluem Guilherme Calmon Nogueira da Gama e Thaís Boia Marçal ${ }^{39}$ não ser razoável permitir que o devedor mantenha um alto padrão de vida, com conforto e comodidade excessivos, em detrimento de seus credores, que podem vir a sofrer um comprometimento de sua dignidade.

De outra banda, não é incomum verificar casos em que o credor se encontra em situação de pobreza, em que sua dignidade ou seu mínimo existencial estão sendo infringidos, e a execução manejada por ele é frustrada unicamente pela impossibilidade de penhora sobre o bem de família. Existindo um conflito entre a dignidade do credor e a dignidade do devedor, não parece razoável que prevaleça a dignidade daquele que se encontra inadimplente com suas obrigações, unicamente com lastro na proteção legislativa conferida ao bem de família. Cabe, então, uma análise detida do caso para identificar os direitos conflitantes.

Portanto, a impenhorabilidade do bem de família impõe limitações ao direito fundamental à tutela executiva, entretanto, não se faz possível restringir a análise a uma verificação legislativa. É patente a existência de um conflito entre direitos fundamentais do credor e do devedor. Daí a necessidade de um juízo de ponderação que leve em conta as

\footnotetext{
38 GAMA, Guilherme Calmon Nogueira da; MARÇAL, Thaís Boia. Penhorabilidade do bem de família "luxuoso" na perspectiva civil-constitucional. Revista Quaestio Iuris, Rio de Janeiro, v. 6, n. 2, 2013, p. 249. Disponível em: https://www.e-publicacoes.uerj.br/index.php/quaestioiuris/issue/view/814. Acesso em: 2 set. 2020.

${ }^{39}$ GAMA, Guilherme Calmon Nogueira da; MARÇAL, Thaís Boia. Penhorabilidade do bem de família "luxuoso" na perspectiva civil-constitucional. Revista Quaestio Iuris, Rio de Janeiro, v. 6, n. 2, 2013, p. 249. Disponível em: https://www.e-publicacoes.uerj.br/index.php/quaestioiuris/issue/view/814. Acesso em: 2 set. 2020.
} 
Rio de Janeiro. Ano 15. Volume 22. Número 3. Setembro a Dezembro de 2021

Periódico Quadrimestral da Pós-Graduação Stricto Sensu em Direito Processual da UERJ

Patrono: José Carlos Barbosa Moreira (in mem.). ISSN 1982-7636. pp. 958-980 www.redp.uerj.br

circunstâncias do caso concreto e observe a incidência do direito à efetividade da execução e dos princípios da proporcionalidade e da razoabilidade. O juízo de ponderação é imperioso para que haja uma adequada aplicação da norma jurídica que confere a impenhorabilidade ao imóvel familiar.

Com base nesse panorama, é possível verificar que o STJ tem mitigado a norma de impenhorabilidade do bem de família, recorrendo a outros critérios além da previsão legislativa, conforme se demonstrará no tópico seguinte.

\section{A MitigaÇÃo da IMPENHORABILIDAde do BEM dE FAMília PELO STJ: CRITÉRIOS QUE MANIFESTAM A APLICAÇÃO DE PRINCÍPIOS FUNDAMENTAIS DO CREDOR NA AVALIAÇÃO DA IMPENHORABILDIADE}

O Superior Tribunal de Justiça ao longo dos anos tem proferido decisões que revelam uma mudança em suas bases fundamentais sobre a incidência da norma de impenhorabilidade do bem de família, com a aplicação das exceções legislativas a essa regra. De fato, cada vez mais, têm sido considerados também os princípios fundamentais do credor quando da avaliação para conferir ou não a proteção ao imóvel do devedor caracterizado como bem de família.

Inicialmente, é relevante constatar que a jurisprudência do STJ havia assumido uma posição contrária à admissibilidade de interpretações extensivas ao rol da Lei n. ${ }^{\circ}$ 8.009/90, conforme demonstra Batista ${ }^{40}$ ao relatar a exegese firmada pelo STJ, expondo decisões em que o rol de exceções à impenhorabilidade é considerado um rol taxativo, insuscetível de interpretação extensiva ${ }^{41}$. Esse posicionamento, contudo, tem sido alterado.

\footnotetext{
40 BATISTA, Fernando Natal. Considerações jurisprudenciais do Superior Tribunal de Justiça sobre a impenhorabilidade do bem de família legal à luz dos princípios da dignidade da pessoa humana e da proteção à moradia. Revista da $A G U$, Brasília, DF, v. 16, n. 3, jul./set. 2017, p. 186-187. Disponível em: https://www.academia.edu/34810070/Considera\%C3\%A7\%C3\%B5es_Jurisprudenciais_Do_Superior_Tribu nal_De_Justi\%C3\%A7a_Sobre_A_Impenhorabilidade_Do_Bem_De_Fam\%C3\%ADlia_Legal_\%C3\%80_Lu z_Dos_Princ\%C3\%ADpios_Da_Dignidade_Da_Pessoa_Humana_E_Da_Prote\%C3\%A7\%C3\%A3o_\%C3\% 80_Moradia. Acesso em: 2 set. 2020.

41 Demonstra esse entendimento a decisão no REsp 1.074.838/SP, que aponta a existência de uma jurisprudência do STJ segundo a qual é impossível conferir interpretação extensiva ao rol de exceções à impenhorabilidade do bem de família estabelecidos na Lei n. ${ }^{\circ}$ 8.009/90 (STJ (4. Turma). REsp 1.074.838/SP. Relator: Min. Luis Felipe Salomão. Julgado em: 23/10/2012. DJe 30/10/2012).
} 
De recentes decisões do STJ, é possível extrair a adoção de outros critérios, além da expressa previsão legal, para excepcionar a impenhorabilidade do bem de família.

Este panorama visa demonstrar o posicionamento que vem se firmando na Corte Superior, pelo reconhecimento da necessidade de conferir efetividade à tutela executiva e à proteção dos direitos fundamentais do credor, que, em determinados casos, podem estar em conflito com os direitos do devedor.

Quando se analisa as decisões mais recentes do STJ sobre a incidência ou não da proteção ao imóvel residencial, constata-se uma clara flexibilidade na regra da impenhorabilidade, diferentemente da rigidez anteriormente pregada pela jurisprudência da referida Corte Superior. É inegável, portanto, que os tribunais têm reinterpretado diversos pontos da norma de vedação geral da impenhorabilidade do bem de família, com a aplicação apenas das exceções previstas em lei.

Uma das exceções que a jurisprudência já sedimentou diz respeito à possibilidade de penhora da vaga de garagem com matrícula própria no registro de imóveis, que não integraria o bem de família, nos termos da Súmula 449 do STJ ${ }^{42}$. Nesse caso, é possível verificar que o posicionamento do STJ é favorável à possibilidade de desfazimento de parte do imóvel residencial (correspondente à parte destinada à guarda de veículo) quando cabível seu desmembramento. Tal hipótese não corresponde às exceções à impenhorabilidade previstas em lei, mas se trata de entendimento sumulado pelo STJ, ao adotar critérios além da previsão legislativa.

Outra importante exceção é o afastamento da impenhorabilidade do bem de família por vontade do proprietário. Embora, inicialmente, o STJ possua posicionamentos aduzindo a impossibilidade de renúncia à impenhorabilidade ${ }^{43}$, tal entendimento tem sido alterado, verificando-se em julgados mais recentes a prevalência na Corte Superior do entendimento de que é possível a disponibilidade do bem de família.

Nesse sentido, quando se trata de imóvel oferecido como garantia real de hipoteca pelo casal ou pela entidade familiar, o STJ tem entendimento de que apenas não se aplica a

\footnotetext{
${ }^{42}$ Súmula 449 do STJ: “A vaga de garagem que possui matrícula própria no registro de imóveis não constitui bem de família para efeito de penhora".

43 “[...] Além disso, registra que o imóvel é o único bem da agravada, sendo impossível a renúncia a impenhorabilidade do bem de família [...]" (STJ (4. Turma). AgRg no AREsp 384.091/MS,. Relator: Ministro Luis Felipe Salomão. Julgado em 19/09/2013. DJe 27/09/2013).
} 
impenhorabilidade quando a dívida constituída beneficiou o casal ou a entidade familiar ${ }^{44}$.

É manifesto que o STJ considera como critério para a verificação da impenhorabilidade se houve ou não benefício à entidade familiar com a disposição do bem de família como garantia de dívida hipotecária. Portanto, para que a proteção legal da impenhorabilidade seja aplicada, não basta simplesmente a incidência da norma, mas é necessário que, no caso, seja comprovado que a entidade familiar (que efetivamente está sendo protegida pela impenhorabilidade) não está obtendo dupla vantagem ao se beneficiar com a obtenção do crédito (que originou a dívida hipotecária) e a vedação da penhora do bem de família.

Fica patente aqui a aplicação do critério da boa-fé do credor, que afirma que não obteve dupla vantagem, que concede imóvel familiar para obter crédito em proveito de sua família, contando com a proteção da lei que impede que o bem de família seja utilizado para pagamento da dívida. Também há clara presença do critério da razoabilidade, ao não se permitir que a norma jurídica seja utilizada como subterfúgio pelo devedor.

Nesse mesmo sentido, encontra-se sumulado o afastamento da impenhorabilidade quando o bem é oferecido pelo proprietário na qualidade de fiador em contrato de locação. Trata-se da Súmula 549 do STJ: "É válida a penhora de bem de família pertencente a fiador de contrato de locação".

Logo, fica notório que o STJ, ao ponderar a impenhorabilidade do imóvel e o direito ao crédito promovido em demanda executiva, tem como critério para a verificação da incidência da proteção legal ao imóvel residencial a boa-fé objetiva do proprietário devedor.

\footnotetext{
44 “ [...] 1. O art. 1. ${ }^{\circ}$ da Lei n. 8.009/1990 instituiu a impenhorabilidade do bem de família, haja vista se tratar de instrumento de tutela do direito fundamental à moradia da família e, portanto, indispensável à composição de um mínimo existencial para uma vida digna, ao passo que o art. $3 .^{\circ}$, inciso $\mathrm{V}$, desse diploma estabelece, como exceção à regra geral, a penhorabilidade do imóvel que tiver sido oferecido como garantia real pelo casal ou pela entidade familiar. 2. No ponto, a jurisprudência desta Casa se sedimentou, em síntese, no seguinte sentido: a) o bem de família é impenhorável, quando for dado em garantia real de dívida por um dos sócios da pessoa jurídica devedora, cabendo ao credor o ônus da prova de que o proveito se reverteu à entidade familiar; e b) o bem de família é penhorável, quando os únicos sócios da empresa devedora são os titulares do imóvel hipotecado, sendo ônus dos proprietários a demonstração de que a família não se beneficiou dos valores auferidos [...]” (STJ (2. Seção). EAREsp 848.498/PR. Relator: Min. Luis Felipe Salomão. Julgado em: 25/04/2018. DJe 07/06/2018). No mesmo sentido: “[...] 1. A exceção do art. $3^{\circ}$, inciso V, da Lei no 8.009/90, que permite a penhora de bem dado em hipoteca, limita-se à hipótese de dívida constituída em favor da entidade familiar [...]" (STJ (3. Turma). REsp 1.141.732/SP. Relatora: Min. Nancy Andrighi. Julgado em: 09/11/2010. DJe 22.11.2010); STJ (3. Turma). AgRg no Ag 1.126.623/SP. Relator: Min. Paulo de Tarso Sanseverino, Julgado em: 16/09/2010. DJe de 06.10.2010; STJ (4. Turma). REsp 1.022.735/RS. Relator: Min. Fernando Gonçalves. Julgado em: 15/12/2009. DJe de 18.02.2010; STJ (4. Turma). REsp 268.690/SP. Relator: Min. Ruy Rosado de Aguiar. Julgado em: 14/12/2000. DJe de 12.03.2001.
} 
Revista Eletrônica de Direito Processual - REDP.

Rio de Janeiro. Ano 15. Volume 22. Número 3. Setembro a Dezembro de 2021

Periódico Quadrimestral da Pós-Graduação Stricto Sensu em Direito Processual da UERJ

Patrono: José Carlos Barbosa Moreira (in mem.). ISSN 1982-7636. pp. 958-980 www.redp.uerj.br

Nesse sentido, já observou Flávio Tartuce, analisando julgado de 2012 (REsp 1.299.580) ${ }^{45}$, que o Superior Tribunal de Justiça tem concluído que a boa-fé, notadamente a de natureza objetiva, deve ser levada em conta na análise da tutela do bem de família, o que representaria uma outra exceção à estudada impenhorabilidade ${ }^{46}$.

Logo, um dos principais critérios que têm sido adotados pelo STJ para avaliar a aplicação, ou não, da impenhorabilidade do bem de família é a boa-fé objetiva do devedor ${ }^{47}$. Trata-se de patente ampliação do rol de exceções da Lei n. ${ }^{\circ}$ 8.009/1990, por se incluir na avaliação do julgador o reconhecimento da boa-fé na atuação devedor, verificando-se se, no caso, a conduta dele não leva ao reconhecimento da prática de atos que não traduzam uma boa-fé objetiva.

Observa-se, assim, que outros critérios, além da simples disposição legislativa, têm sido avaliados pelo STJ quando da análise da impenhorabilidade no caso concreto.

A boa-fé objetiva, portanto, tem sido considerada quando da análise da impenhorabilidade do bem de família ${ }^{48}$. Leva-se em conta a boa-fé do proprietário, que não se pode valer da proteção legal ao bem de família para obter uma vantagem inicial (por exemplo, acesso ao crédito), mas, quando diante do inadimplemento, vale-se da lei para impedir que o imóvel oferecido livremente e conscientemente como garantia não sofra atos

\footnotetext{
${ }^{45}$ Trata-se do REsp 1.299.580: “[...] 1. Não há, em nosso sistema jurídico, norma que possa ser interpretada de modo apartado aos cânones da boa-fé. Ao alienar todos os seus bens, menos um, durante o curso de processo que poderia levá-lo à insolvência, o devedor não obrou apenas em fraude à execução: atuou também com fraude aos dispositivos da Lei 8.009/90, uma vez que procura utilizar a proteção conferida pela Lei com a clara intenção de prejudicar credores.2. Nessas hipóteses, é possível, com fundamento em abuso de direito, afastar a proteção conferida pela Lei 8.009/90 [...]" (STJ (3, Turma) REsp 1.299.580 Relatora: Min. Nancy Andrighi. Julgado em: 20.03.2012). Entendeu a Corte que a impenhorabilidade não prevalece nas hipóteses em que o devedor atua de má-fé, alienando todos os seus bens e fazendo restar apenas o imóvel de residência.

${ }^{46}$ TARTUCE, Flávio. A boa-fé como exceção à proteção do bem de família legal. 2020, p. 3. Disponível em: https://www.academia.edu/43954995/A_BOA_F\%C3\%89_COMO_EXCE\%C3\%87\%C3\%830_\%C3\%80_P ROTE\%C3\%87\%C3\%830_DO_BEM_DE_FAM\%C3\%8DLIA_LEGAL. Acesso em: 2 set. 2020.

47 “'[...] A boa-fé do devedor é determinante para que possa se socorrer do favor legal, reprimindo-se quaisquer atos praticados no intuito de fraudar credores ou retardar o trâmite dos processos de cobrança. $\mathrm{O}$ fato de $\mathrm{o}$ imóvel dado em garantia ser o único bem da família certamente é sopesado ao oferecê-lo em hipoteca, ciente de que o ato implica renúncia à impenhorabilidade. Assim, não se mostra razoável que depois, ante à sua inadimplência, o devedor use esse fato como subterfúgio para livrar o imóvel da penhora. A atitude contraria a boa-fé ínsita às relações negociais, pois equivaleria à entrega de uma garantia que o devedor, desde o início, sabia ser inexequível, esvaziando-a por completo [...]” (STJ (3. Turma). REsp 1.141.732/SP. Relatora: Min. Nancy Andrighi. Julgado em: 09/11/2010. DJe 22.11.2010).

${ }^{48}$ TARTUCE, Flávio. A boa-fé como exceção à proteção do bem de família legal. 2020, p. 5. Disponível em: https://www.academia.edu/43954995/A_BOA_F\%C3\%89_COMO_EXCE\%C3\%87\%C3\%83O_\%C3\%80_P ROTE\%C3\%87\%C3\%830_DO_BEM_DE_FAM\%C3\%8DLIA_LEGAL. Acesso em: 2 set. 2020.
} 
Revista Eletrônica de Direito Processual - REDP.

Rio de Janeiro. Ano 15. Volume 22. Número 3. Setembro a Dezembro de 2021

Periódico Quadrimestral da Pós-Graduação Stricto Sensu em Direito Processual da UERJ

Patrono: José Carlos Barbosa Moreira (in mem.). ISSN 1982-7636. pp. 958-980

www.redp.uerj.br

de penhora e de expropriação ${ }^{49}$. Nesse sentido, posicionou-se o STJ em recente julgado, asseverndo que a proteção conferida ao bem de família pela Lei 8.009/90 não importa em sua inalienabilidade, sendo possível a disposição do imóvel pelo proprietário, não devendo ser tolerada a utilização abusiva de tal direito, com violação do princípio da boa-fé objetiva ${ }^{50}$.

Mas ainda há outros entendimentos relevantes que foram sedimentados pelo STJ nos últimos anos, flexibilizando a impenhorabilidade, privilegiando maior compatibilidade entre os direitos em conflito. Como exemplo, a possibilidade de recair a penhora sobre parte do bem de família, quando possível seu desmembramento, sem que isso importe em descaracterização do imóvel ${ }^{51}$.

Mesmo ainda havendo resistência em alguns $\operatorname{casos}^{52}$, os posicionamentos do STJ sobre a impenhorabilidade do bem de família denotam clara admissão de outros critérios para avaliar a regularidade da proteção do bem de família para além da mera previsão legal.

\footnotetext{
${ }^{49}$ Assim compreendem Fredie Didier Jr., Leonardo Carneiro da Cunha, Paula Sarno Braga e Rafael Alexandria Oliveira: "o oferecimento de bem de família à penhora pelo executado impede futura alegação de impenhorabilidade desse mesmo bem" (DIDIER JR., Fredie; CUNHA, Leonardo Carneiro da; BRAGA, Paula Sarno; OLIVEIRA, Rafael Alexandria. Curso de Direito Processual Civil: execução. 7. ed. Salvador: Juspodivm, 2017. v. 5, p. 842-843).

50 “[...] 1. A proteção legal conferida ao bem de família pela Lei n. 8.009/90 não pode ser afastada por renúncia do devedor ao privilégio, pois é princípio de ordem pública, prevalente sobre a vontade manifestada $\mathrm{AgRg}$ nos EREsp 888.654/ES, Rel. Ministro João Otávio de Noronha, Segunda Seção, julgado em 14.03.2011, DJe 18.03.2011). 2. Nada obstante, à luz da jurisprudência dominante das Turmas de Direito Privado: (a) a proteção conferida ao bem de família pela Lei n\# 8.009/90 não importa em sua inalienabilidade, revelando-se possível a disposição do imóvel pelo proprietário, inclusive no âmbito de alienação fiduciária; e (b) a utilização abusiva de tal direito, com evidente violação do princípio da boa-fé objetiva, não deve ser tolerada, afastando-se o benefício conferido ao titular que exerce o direito em desconformidade com o ordenamento jurídico (STJ (4. Turma). REsp 1.595.832/SC. Relator: Min. Luis Felipe Salomão. Julgado em: 29.10.2019. DJe 04/02/2020).

51 “[...] 2. A fração de imóvel indivisível pertencente ao executado, protegida pela impenhorabilidade do bem de família, não pode ser penhorada sob pena de desvirtuamento da proteção erigida pela Lei n. ${ }^{\circ}$ 8.009/90.

3. Admite-se, excepcionalmente, a penhora de parte do imóvel quando for possível o seu desmembramento em unidades autônomas, sem descaracterizá-lo, levando em consideração, com razoabilidade, as circunstâncias e peculiaridades do caso. Situação não demonstrada no caso dos autos.[...]" (STJ (3. Turma). AgInt no REsp 1.485.839/RJ. Relator: Min. Moura Ribeiro. Julgado em: 19/08/2019. DJe 21/08/2019). Outras decisões no mesmo sentido: STJ. REsp 1.765.329/SP. Relator: Min. Moura Ribeiro. Julgado em: 23/05/2020. DJe 28/05/2020; STJ. AgInt no REsp 1.485.839/RJ. Relator: Min. Moura Ribeiro. Julgado em: 19/08/2019. DJe 21/08/2019; STJ (4. Turma). AgInt no REsp 1.663.895/PR. Relator: Min. Marco Buzzi. Julgado em: 30/09/2019. DJe 07/10/2019; STJ (4. Turma). AgInt no AREsp 573.226/SP. Relator: Min. Raul Araújo. Julgado em: 02/02/2017. DJe 10/02/2017.

${ }^{52}$ Sobre a possibilidade de se afastar a impenhorabilidade quando o imóvel é de alto valor, o STJ ainda tem resistido em ponderar outros critérios além da normatividade expressa, conforme o seguinte julgado: STJ (4. Turma). AgInt no REsp 1.520.498/SP. Relator: Min. Lázaro Guimarães (Desembargador convocado do TRF 5. ${ }^{a}$ Região). Julgado em: 27/02/2018. DJe 02/03/2018). Apesar disso, a doutrina tem construído pensamentos em sentido contrário, como o exposto por Fredie Didier Jr., Leonardo Carneiro da Cunha, Paula Sarno Braga e Rafael Alexandria Oliveira, que defendem a plena possibilidade de afastamento, in casu, da norma legal em detrimento da compatibilização do direito fundamental à moradia com a efetividade da tutela executiva (DIDIER JR., Fredie; CUNHA, Leonardo Carneiro da; BRAGA, Paula Sarno; OLIVEIRA, Rafael Alexandria. Curso de Direito Processual Civil: execução. 7. ed. Salvador: Juspodivm, 2017. v. 5, p. 67).
} 
A boa-fé objetiva é absolutamente presente nessas decisões, mas também se revelam como critérios essenciais a verificação da proporcionalidade e da razoabilidade, como parâmetros primordiais para avaliar a incidência da proteção normativa do bem de família.

Verifica-se uma modificação nos critérios decisórios que não se limitam mais a mera subsunção do fato à norma, mas também se consideram outras balizas, que prestigiam a socialidade e a eticidade nas relações privadas, princípios do Código Civil de 2002.

Neste sentido, assevera Araken de Assis que as exceções à impenhorabilidade da residência familiar reclamam cuidado e atenção do órgão judiciário ao aplicá-las, considerando outros fatores, como o princípio da proporcionalidade. Exemplo bastante claro é a execução do crédito resultante das despesas condominiais, sendo incompatível isentar a residência familiar das sanções do inadimplemento, todavia usufruindo das benesses pagas pelas despesas comuns, transferindo encargos próprios para seus vizinhos. Não parece justificável, sob qualquer ponto de vista, defender a impenhorabilidade nesta hipótese ${ }^{53}$.

A jurisprudência do STJ, portanto, mesmo considerando o rol do artigo $3 .^{\circ}$ da Lei n. $^{\circ}$ 8.009/1990, tem-se distanciado da fundamentação segundo a qual esse rol é taxativo e com interpretação restritiva. O que se tem verificado é a aplicação de diversas interpretações da lei, as quais avaliam outros critérios para confirmação (ou afastamento) da impenhorabilidade do bem de família, como a boa-fé objetiva, a razoabilidade e a proporcionalidade.

Cada vez mais, têm sido levadas em consideração a livre disponibilidade pelo proprietário e a efetiva prática de atos de boa-fé (afastando-se, inclusive, critérios subjetivos, como a intenção, o dolo ou a culpa). Isso confere grande importância à adoção de critérios como a proporcionalidade e a razoabilidade, a fim de que sempre prevaleça na decisão a melhor ponderação de princípios.

Compreende-se que a avaliação desses critérios manifesta uma interpretação da norma infralegal de acordo com uma ponderação de princípios fundamentais, em especial, daqueles que conferem proteção ao credor. A avaliação da efetividade da tutela executiva como um princípio fundamental é clara no STJ, ao ponderar outros critérios para verificar a existência ou não da impenhorabilidade no caso concreto. Mas o STJ não se limita a isso, pois também é possível identificar a manifestação do princípio fundamental da dignidade da

\footnotetext{
${ }^{53}$ ASSIS, Araken de. Manual de execução. 18. ed. São Paulo: Revista dos Tribunais, 2016, p. 376-377.
} 
pessoa humana do credor, quando do afastamento das hipóteses de impenhorabilidade pela ausência de boa-fé objetiva do devedor.

Os novos critérios considerados pelo STJ denotam uma clara abertura ao debate para além do rol taxativo previsto em lei, aprofundando a análise da impenhorabilidade de acordo com outros fatores relevantes para a resolução do caso. É de se questionar, inclusive, se ainda pode-se tratar de um rol taxativo de impenhorabilidades, na medida em que os julgados têm, reiteradas vezes, flexibilizado o dispositivo legal, assumindo novas interpretações e adotando novos critérios de análise da existência da proteção legal ao imóvel familiar.

\section{CONSIDERAÇÕES FINAIS}

O bem de família apresenta-se na legislação nacional como instituto que visa garantir direitos constitucionais como a dignidade da pessoa humana, a moradia, a preservação da entidade familiar e o mínimo existencial, e a previsão de sua impenhorabilidade tem caráter essencial. Mas, como nenhum direito fundamental pode ser absoluto ou superior aos demais, a Lei n. ${ }^{\circ}$ 8.009/1990 visa expor as exceções à regra da impenhorabilidade, apresentando um rol tido como taxativo de créditos que permitem a penhora do imóvel. Trata-se, assim, de dar ao legislador a opção de indicar expressamente apenas alguns tipos de crédito que prevalecem sobre a garantia constitucional da moradia.

Com o desenvolvimento da sociedade ao longo dos anos e a consagração da finalidade constitucional que as normas devem visar, outros direitos também relevantes passam a ser objeto de avaliação da regularidade, in casu, da aplicação da impenhorabilidade do bem de família, como a livre disponibilidade pelo proprietário, a boa-fé do devedor, a proporcionalidade e a razoabilidade, a própria dignidade do credor, tudo tendo em vista a busca do princípio da efetividade da tutela jurisdicional.

A adoção de súmulas ou mesmo de entendimentos reiterados já consolidados demonstra que o STJ tem buscado distanciar-se da lei e aproximar-se dos casos concretos, propondo uma interpretação que busca compatibilizar a proteção conferida pela impenhorabilidade com os direitos do credor igualmente válidos. Somente uma análise in casu permitirá sopesar esses princípios fundamentais. 
Assim, o presente trabalho permitiu constatar que tem havido um afastamento da interpretação restritiva da norma do artigo $3 .^{\circ}$ da Lei n. ${ }^{\circ}$ 8.009/1990. Os julgados do STJ evidenciam uma flexibilização da interpretação do referido artigo. De fato, o STJ tem adotado outros critérios que balizam direitos igualmente relevantes, como a efetividade da tutela executiva e a própria dignidade do credor, que devem ser prestigiados quando do embate com a proteção da dignidade e da moradia do executado. Em determinadas situações, cumpre dar uma maior relevância aos direitos do credor, de modo a compatibilizá-los, em certa medida, com a preservação da moradia do devedor.

Entende-se, portanto, que o reconhecimento da efetividade da tutela executiva como direito fundamental constitucional e processual é um dos fatores fundamentais para a adoção de outros critérios para avaliar a incidência da impenhorabilidade do bem de família. A ponderação de direitos fundamentais, como já tem sido praticada, é essencial para que o Judiciário promova decisões constitucionalmente adequadas, debatendo o choque entre os direitos fundamentais que lastreiam a impenhorabilidade do bem de família e aqueles direitos que fundamentam os direitos do credor, como a efetividade da tutela executiva, a dignidade da pessoa humana, a proporcionalidade, a razoabilidade, a boa-fé e outros direitos do credor que se manifestarem no caso concreto.

\section{REFERÊNCIAS}

ASSIS, Araken de. Manual de execução. 18. ed. São Paulo: Revista dos Tribunais, 2016. BATISTA, Fernando Natal. Considerações jurisprudenciais do Superior Tribunal de Justiça sobre a impenhorabilidade do bem de família legal à luz dos princípios da dignidade da pessoa humana e da proteção à moradia. Revista da AGU, Brasília, DF, v. 16, n. 3, p. 179-196, jul./set. 2017. Disponível em: https://www.academia.edu/34810070/Considera\%C3\%A7\%C3\%B5es_Jurispruden ciais_Do_Superior_Tribunal_De_Justi\%C3\%A7a_Sobre_A_Impenhorabilidade_D o_Bem_De_Fam\%C3\%ADlia_Legal_\%C3\%80_Luz_Dos_Princ\%C3\%ADpios_Da _Dignidade_Da_Pessoa_Humana_E_Da_Prote\%C3\%A7\%C3\%A3o_\%C3\%80_M oradia. Acesso em: 2 set. 2020. 
BUENO, Cassio Scarpinella. Novo Código de Processo Civil Anotado. São Paulo: Saraiva, 2015 .

CAMBI, Eduardo; HAAS, Adriane; Schmitz, Nicole. Normas fundamentais no novo Código de Processo Civil. Revista de Processo, São Paulo, v. 44, n. 290, p. 95-132, abr. 2019.

CUNHA, Leonardo Carneiro da. A previsão do princípio da eficiência no projeto do novo Código de Processo Civil brasileiro. Revista de Processo, São Paulo, v. 39, n. 233, p. 65-84, jul. 2014.

DIAS, Jean Carlos; MOUTA, José Henrique; SILVA, Michel Ferro e; SILVA, Adelvan Oliverio; HOMCI, Arthur Laércio; PEREIRA, Bernardo Augusto da Costa. Curso de Processo Civil: processo de conhecimento. Rio de Janeiro: Lumen Juris, 2016.

DIDIER JR., Fredie. Curso de Direito Processual Civil: introdução ao Direito Processual Civil, parte geral e processo de conhecimento. 19. ed. Salvador: Juspodivm, 2017.

DIDIER JR., Fredie; CUNHA, Leonardo Carneiro da; BRAGA, Paula Sarno; OLIVEIRA, Rafael Alexandria. Curso de Direito Processual Civil: execução. 7. ed. Salvador: Juspodivm, 2017. v. 5.

FARIA, Guilherme Henrique Lage. Negócios processuais no modelo constitucional de processo. Salvador: Juspodivm, 2016.

GAMA, Guilherme Calmon Nogueira da; MARÇAL, Thaís Boia. Penhorabilidade do bem de família "luxuoso" na perspectiva civil-constitucional. Revista Quaestio Iuris, Rio de Janeiro, v. 6, n. 2, p. 240-256, 2013. Disponível em: https://www.epublicacoes.uerj.br/index.php/quaestioiuris/issue/view/814. Acesso em: 2 set. 2020.

GÓES, Gisele Santos Fernandes. Processo civil cooperativo. A Leitura: Caderno da Escola Superior da Magistratura do Estado do Pará, Belém, v. 5, n. 9, p. 106-113, nov. 2012.

MARINONI, Luiz Guilherme; ARENHART, Sérgio Cruz; MITIDIERO, Daniel. Novo curso de processo civil: teoria do processo civil. 3. ed. rev., atual. e ampl. São Paulo: Revista dos Tribunais, 2017. v. 1.

MAZZEI, Rodrigo Reis; ROSADO, Marcelo da Rocha. A cláusula geral de efetividade e as medidas indutivas no CPC/15. In: TALAMINI, Eduardo; MINAMI, Marcos Youji (coord.). Medidas executivas atípicas. Coleção Grandes Temas do Novo CPC. Vol. 11. Salvador: JusPodivm, 2018.

MEDIDA, Jose Miguel Garcia. 5. ed. Execução. São Paulo: Revista dos Tribunais, 2017. 
MINAMI, Marcos Youji. Tradição jurídica e efetivação das decisões judiciais: repercussões da tradição civil law na efetivação das decisões no Direito Brasileiro. In: TALAMINI, Eduardo; MINAMI, Marcos Youji (org.). Medidas executivas atípicas. Salvador: Juspodivm, 2018. p. 559-590. (Coleção Grandes Temas do NCPC, 11).

OLIVEIRA, Maria Fernanda César Las Casas de; TOLEDO, Renata Maria Silveira; SANTOS, João Paulo Marques dos. O Superior Tribunal de Justiça e a proteção do bem de família: ativismo judicial ou preservação do patrimônio mínimo? Revista da Defensoria Pública da União, Brasília, DF, n. 12, p. 247-271, jan./dez. 2019. Disponível em: https://www.academia.edu/40976340/O_SUPERIOR_TRIBUNAL_DE_JUSTI\%C 3\%87A_E_A_PROTE\%C3\%87\%C3\%830_DO_BEM_DE_FAM\%C3\%8DLIA_A TIVISMO_JUDICIAL_OU_PRESERVA\%C3\%87\%C3\%83O_DO_PATRIM\%C3 \%94NIO_M\%C3\%8DNIMO. Acesso em: 2 set. 2020.

RODRIGUES, Marcelo Abelha. Fundamentos da tutela executiva. Brasília, DF: Gazeta Jurídica, 2018.

SICA, Heitor Vitor Mendonça. Tendências evolutivas da execução civil brasileira. [2014?]. Disponível em: https://edisciplinas.usp.br/pluginfile.php/4425295/mod_resource/content/1/2014__Tendencias_evolutivas_da_execucao.pdf. Acesso em: 2 set. 2020.

SOUZA, Miguel Teixeira de. A reforma da acção executiva. Lisboa: Lex, 2004.

TARTUCE, Flávio. A boa-fé como exceção à proteção do bem de família legal. 2020. Disponível em: https://www.academia.edu/43954995/A_BOA_F\%C3\%89_COMO_EXCE\%C3\%8 7\%C3\%830_\%C3\%80_PROTE\%C3\%87\%C3\%83O_DO_BEM_DE_FAM\%C3\% 8DLIA_LEGAL. Acesso em: 2 set. 2020.

THEODORO JUNIOR, Humberto. Processo de execução e cumprimento da sentença. 29. ed. São Paulo: Leud, 2017.

ZARONI, Bruno Marzullo; VITORELLI, Edilson. Reforma e efetividade da execução no novo CPC. In: MACÊDO, Lucas Buril de; PEIXOTO, Ravi; FREIRE, Alexandre (org). Execução. 2. ed. Salvador: Juspodivm, 2016. p. 53-81. (Coleção Novo CPC Doutrina Selecionada, 5). 